Original article

\title{
MATERNAL HAEMOGLOBIN LEVEL AND ITS ASSOCIATION WITH PREGNANCY OUTCOME AMONG MOTHERS
}

\author{
Soumyamol Francis ${ }^{1} \&$ Sabitha Nayak ${ }^{2}$ \\ ${ }^{1}$ Il year M.Sc. (N), ${ }^{2}$ Vice Principal, Professor, Department of OBG Nursing, \\ Nitte Usha Institute of Nursing Sciences, Nitte University, Deralakatte, Mangalore-575 018, India \\ Correspondence \\ Soumyamol Francis \\ II year M.Sc Nursing, Department of OBG Nursing, Nitte Usha Institute of Nursing Sciences, \\ Nitte University, Mangalore - 575 018, India \\ Mobile : +9199018 84823, E-mail : soumyamolfrancis@gmail.com
}

\section{Abstract :}

The study was conducted to assess the maternal haemoglobin level and its association with pregnancy outcome among mothers . The study design adopted was descriptive design, 100 antenatal mothers were selected by purposive sampling. The demographic Proforma were collected from the women by interview and Apgar scoring system,New Ballard score and infantometer used for assessing the pregnancy outcome. Data obtained in these areas were analysed by descriptive and inferential statistics. A significant relation was found between maternal haemoglobin level and pregnancy outcome such as type of delivery $(0.039, \mathrm{P}<0.05)$ and birth weight $(.001, \mathrm{P}<0.05)$ and a significant association was found between maternal haemoglobin and selected demographic variables such as income $(.037, \mathrm{p}<0.05)$ and $\mathrm{BMI}(.039, \mathrm{p}<0.05)$. The findings of the study revealed that there is a association between maternal haemoglobin level and pregnancy outcome.

Keywords : Haemoglobin level, pregnancy outcome, BMI, birth weight.

\section{Introduction :}

A healthy pregnancy is like a healthy plant. A healthy pregnancy is one that both the mother and the baby come to a positive outcome. Pregnancy is a long and very special journey for the woman. Labor, the culmination of pregnancy, is an event with great psychological and emotional meaning for the mother and her family. ${ }^{1}$

In early pregnancy haemoglobin concentration drops as plasma volume expansion outspaces expansion of the red cell mass, while in late pregnancy, plasma volume ceases to expand and haemoglobin concentration rise if iron stores are adequate. $^{2}$ Thus the relation of haemoglobin concentration to birth outcome will probably depend on when the haemoglobin is

\begin{tabular}{|c|}
\hline Access this article online \\
\hline Quick Response Code \\
\hline
\end{tabular}

measured. Maternal anaemia in pregnancy is commonly considered as risk factor for poor pregnancy outcome and can threaten the life of mother and foetus.
However, the extent to which the maternal haemoglobin concentration affects the foetal weight and foetal outcome is still uncertain. Studies have shown a strong association between low maternal haemoglobin levels before delivery and adverse foetal outcome. ${ }^{4}$ Low and high maternal haematocrit can influence outcome of pregnancy. Anaemia is frequently observed during pregnancy. The prevalence of anaemia among pregnant women is $55.9 \%$ worldwide and varies between $35 \%$ and $100 \%$ in developing countries. Recent studies emphasized an association between high maternal haematocrit or haemoglobin values and adverse pregnancy outcome. ${ }^{3}$

\section{Background of the study:}

Anaemia is defined as reduction in circulating haemoglobin mass below the critical level. The normal haemoglobin $(\mathrm{Hb})$ concentration in the body is between 12-14 grams percent. WHO has accepted up to $11 \mathrm{gm}$ percent as the normal haemoglobin level in pregnancy. Therefore any haemoglobin level below 11gm in pregnancy should be considered as anaemia. However in India and most of the other developing countries the lower limit is often 
accepted as 10 gms percent. Anaemia during pregnancy is defined as a haemoglobin level <11 g / dL. Anaemia in pregnancy is a major public health problem in the developing countries and it accounts for $95 \%$ of anaemic pregnancies in the whole world. Both, low (<7 g/dl) and high (>14.5 g/dl), maternal hemoglobin $(\mathrm{Hb})$ levels have been related to poor pregnancy outcome. ${ }^{5}$

In developing countries maternal anemia during pregnancy has been reported to increase the risk of unfavorable fetal outcome. According to the standard laid down by WHO, anemia in pregnancy is present when the haemoglobin concentration in the peripheral blood is $11 \mathrm{gm} / 100 \mathrm{ml}$ or less. Amount of iron transferred to the fetus is unaffected even if the mother suffers from iron deficiency anaemia, but the incidence of low birth weight babies and pre mature births are common. ${ }^{6}$

\section{Statement of the problem :}

"A study on maternal haemoglobin level and its association with pregnancy outcome among mothers admitted in a selected hospital ,mangalore".

\section{Objectives of the study}

- To assess the Haemoglobin level among mothers.

- To determine the maternal Haemoglobin level on pregnancy outcome.

- To find the association between maternal Haemoglobin level with selected demographic variables.

\section{Review of literature :}

A cohort study was conducted to evaluate the maternal haemoglobin and perinatal outcome at Railway Hospital, Rawalpindi, Pakistan on 860 pregnant mothers out of which 402 were anaemic. The results showed that mothers with anaemia had higher risk of low birth weight, pre-term delivery, intrauterine foetal death, low apgar score, and asphyxia. The risk of pre-term delivery was 3.4 times and that for low birth weight was 1.8 times more in anaemic mothers. Neonates of anaemic women had 1.7 times increased risk of low Apgar Score at one minute and 2.2 times increased risk of intrauterine foetal death than nonanaemic mothers. The study concluded that pregnant mothers with anaemia had higher risk of both maternal and foetal complications. ${ }^{7}$

A study was conducted on the effect of maternal iron deficiency anaemia on foetal growth in Banaras Hindu university, Varanasi on 54 anaemic ( $\mathrm{Hb}<11 \mathrm{gm} \%$ ) live births at term gestation. The maternal iron status was assessed by serum ferritin estimation. The birth weight, head circumference, chest circumference, mid arm circumference and crown heel length were significantly low in infants born to women with moderate and severe anaemia in comparison to infants born to non anaemic women. The growth retarding effect of maternal anaemia was more on foetal birth weight and mid arm circumference than on other anthropometric indices of the newborn. ${ }^{8}$

\section{Purpose of the study:}

Anaemia can be considered as most common and important problem among pregnant women, which adversely affect the maternal and neonatal outcome. The investigator from her clinical experience realized that more often anemic mothers will have poor maternal and fetal outcome. Many studies have been conducted in the area of effect of anaemia in pregnancy on fetal outcome and maternal outcome. There is a dearth of research literature in the area of comparative study in Indian setting. Hence it was felt necessary to compare the maternal and neonatal outcome in gravid women with changes in the haemoglobin concentration. So the investigator is interested to identify the relationship between maternal haemoglobin level and maternal outcome in her setting.

\section{Materials and Methods :}

The study design adopted was descriptive design. Population comprised of mothers who are in the labour in selected hospitals at Mangalore. Purposive sampling technique was used for selection of 100 sample.

The information regarding the demographic Proforma were collected from the women by interview and Pregnancy outcome was assessed by attending the labour and maturity of the new born was assessed by New Ballard 
score,infantometer was used to check the baby weight, Apgar score at one and five minutes was assessed by Apgar scoring system. Data obtained in these areas were analysed by frequency percentage and fishers exact test.

\section{Results :}

The findings are discussed under the following headings.

\section{Section 1: Description of demographic characteristics}

Table 1: Distribution of samples according to the demographic characteristics

$\mathrm{n}=100$

\begin{tabular}{|c|c|c|c|}
\hline SI.No & $\begin{array}{l}\text { Demographic } \\
\text { Characteristics }\end{array}$ & Frequency (f) & Percentage (\%) \\
\hline 1 & Age & & \\
\hline 1.1 & $<20$ yrs & 3 & $3 \%$ \\
\hline 1.2 & $20-25$ yrs & 59 & $59 \%$ \\
\hline 1.3 & $26-30$ yrs & 33 & $33 \%$ \\
\hline 1.4 & $>30$ yrs & 5 & $5 \%$ \\
\hline 2 & Education & & \\
\hline 2.1 & Primary education & 24 & $24 \%$ \\
\hline 2.2 & Highschool & 36 & $36 \%$ \\
\hline 2.3 & PUC & 37 & $37 \%$ \\
\hline 2.4 & Graduate and above & 3 & $3 \%$ \\
\hline 3 & Religion & & \\
\hline 3.1 & Hindu & 73 & $73 \%$ \\
\hline 3.2 & Christian & 4 & $4 \%$ \\
\hline 3.3 & Muslim & 23 & $23 \%$ \\
\hline 3.4 & Others & 0 & $0 \%$ \\
\hline 4 & Family income, in rs & & \\
\hline 4.1 & $<4000$ & 6 & $17 \%$ \\
\hline 4.4 & $4000-7000$ & 52 & $25 \%$ \\
\hline 4.5 & $7001-10000$ & 25 & $52 \%$ \\
\hline 4.7 & $10,001-15,000$ & 17 & $6 \%$ \\
\hline 5 & Type of residence & & \\
\hline 5.1 & Rural & 71 & $71 \%$ \\
\hline 5.2 & Urban & 29 & $29 \%$ \\
\hline 6 & Age at marriage & & \\
\hline 6.1 & $<20$ yrs & 20 & $20 \%$ \\
\hline 6.2 & 20-25yrs & 75 & $75 \%$ \\
\hline 6.3 & $26-30 y r s$ & 4 & $4 \%$ \\
\hline 6.4 & $>30 y r s$ & 1 & $1 \%$ \\
\hline 7 & Duration of married life & & \\
\hline 7.1 & $<1 \mathrm{yr}$ & 23 & $23 \%$ \\
\hline 7.2 & $1-3$ yrs & 53 & $53 \%$ \\
\hline 7.3 & $>3 y r s$ & 24 & $24 \%$ \\
\hline 8 & Weight & & \\
\hline 8.1 & $40-50 \mathrm{~kg}$ & 19 & $19 \%$ \\
\hline 8.2 & $51-60 \mathrm{~kg}$ & 67 & $67 \%$ \\
\hline 8.3 & $61-70 \mathrm{~kg}$ & 12 & $12 \%$ \\
\hline 8.4 & $>70 \mathrm{~kg}$ & 2 & $2 \%$ \\
\hline 9 & BMI & & \\
\hline 9.1 & Over weight & 3 & $3 \%$ \\
\hline 9.2 & Normal & 81 & $81 \%$ \\
\hline
\end{tabular}

\begin{tabular}{|c|l|c|c|}
\hline SI.No & $\begin{array}{l}\text { Demographic } \\
\text { Characteristics }\end{array}$ & Frequency (f) & Percentage (\%) \\
\hline 9.3 & Under weight & 16 & $16 \%$ \\
\hline 9.4 & Obese & 0 & $0 \%$ \\
\hline 10 & Gravida & & \\
\hline 10.1 & $\mathrm{G}_{1}$ & 67 & $67 \%$ \\
\hline 10.2 & $\mathrm{G}_{2}$ & 32 & $32 \%$ \\
\hline 10.3 & $\geq \mathrm{G}_{3}$ & 1 & $1 \%$ \\
\hline 11 & Abortion & & \\
\hline 11.1 & Nil & 78 & $78 \%$ \\
\hline 11.2 & 1 & 18 & $18 \%$ \\
\hline 11.3 & 2 & 3 & $3 \%$ \\
\hline 11.4 & $>=3$ & 1 & $1 \%$ \\
\hline
\end{tabular}

Section 2: Descriptions of pregnancy outcome characteristics

Table 2: Distribution of samples according to the pregnancy outcome characteristics

$\mathrm{n}=100$

\begin{tabular}{|c|c|c|c|}
\hline SI.No & \begin{tabular}{|l|} 
Demographic outcome \\
Characteristics
\end{tabular} & Frequency (f) & Percentage (\%) \\
\hline 1 & Primary PPH & & \\
\hline 1.1 & Yes & 1 & $1 \%$ \\
\hline 1.2 & No & 99 & $99 \%$ \\
\hline 2 & Type of delivery & & \\
\hline 2.1 & $\begin{array}{l}\text { Normal vaginal delivery } \\
\text { with episiotomy }\end{array}$ & 63 & $63 \%$ \\
\hline 2.2 & $\begin{array}{l}\text { Normal vaginal delivery } \\
\text { without episiotomy }\end{array}$ & 3 & $3 \%$ \\
\hline 2.3 & LSCS & 32 & $32 \%$ \\
\hline 2.4 & Instrumental delivery & 2 & $2 \%$ \\
\hline 3 & Birth weight & & \\
\hline 3.1 & $<2.5 \mathrm{~kg}$ & 14 & $14 \%$ \\
\hline 3.2 & $2.5-3 \mathrm{~kg}$ & 50 & $50 \%$ \\
\hline 3.3 & $3.1-3.5 \mathrm{~kg}$ & 31 & $31 \%$ \\
\hline 3.2 & $>3.5 \mathrm{~kg}$ & 5 & $5 \%$ \\
\hline 4 & \multicolumn{2}{|c|}{ Gestational age of the newborn } & \\
\hline 4.1 & $<37$ wks & 4 & $4 \%$ \\
\hline 4.2 & $37-40$ wks & 85 & $85 \%$ \\
\hline 4.1 & $>40$ wks & 11 & $11 \%$ \\
\hline 5 & Intrauterine death & & \\
\hline 5.1 & Yes & 1 & $1 \%$ \\
\hline 5.2 & No & 99 & $99 \%$ \\
\hline 6 & Still birth & & \\
\hline 6.1 & Yes & 1 & $1 \%$ \\
\hline 6.2 & No & 99 & $99 \%$ \\
\hline 7 & Apgar score at 1 minute & & \\
\hline 7.1 & No depression & 91 & $91 \%$ \\
\hline 7.1 & Mild depression & 7 & $7 \%$ \\
\hline 7.2 & Severe depression & 0 & $0 \%$ \\
\hline 8 & Apgar score at 5 minute & & \\
\hline 8.1 & No depression & 95 & $95 \%$ \\
\hline 8.2 & Mild depression & $3 \%$ & $3 \%$ \\
\hline 8.3 & Severe depression & 0 & $0 \%$ \\
\hline
\end{tabular}


Section 3: Assess the maternal haemoglobin level among mothers

$n=100$

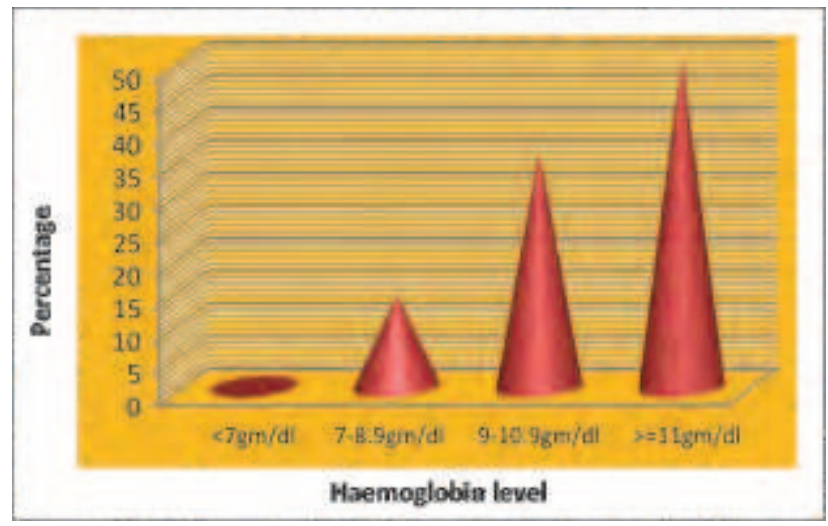

Table 4: Mean and SD of blood haemoglobin level among antenatal mothers

$n=100$

Section 4: Determine the maternal haemoglobin level on pregnancy outcome

To determine the maternal haemoglobin level and pregnancy outcome like primary postpartum haemorrhage ,type of delivery, birth weight of the new born, gestational age of the newborn ,intrauterine death, preterm birth, still birth, Apgar Score at 1 minute and 5 minutes following null hypothesis was formulated;

$\mathrm{HO}_{1}$ - There will be no significant relationship between maternal haemoglobin level and pregnancy outcome

The hypothesis was tested using Fisher's exact test. The haemoglobin score were categorized as $<7 \mathrm{gm} / \mathrm{dl}$, 7 $8.9 \mathrm{gm} / \mathrm{dl}, 9-10.9 \mathrm{gm} / \mathrm{dl}, \geq 11 \mathrm{gm} / \mathrm{dl}$. The value of Fisher's exact was calculated to analyze the relationship between maternal haemoglobin level and pregnancy outcome.

$p$ values of the fisher's tests for the pregnancy outcome variables like type of delivery(.039,p<0.05), birth weight $(.001, p<0.05)$ is less than the 0.05 level of significant .Hence the null hypothesis is rejected this variables and interpreted that there is a significant relationship between these variables and maternal haemoglobin level .But the calculated values of fisher's test variables like PPH(.638,p>0.05) gestational age of newborn (.986, p>0.05), IUD (.500,p>0.05), still birth(1.00,p>0.05), Apgar Score at 1 minute $(.443, p>0.05)$ and Apgar Score at 5 minutes $(1.00, p>0.05)$ is greater than the 0.05 level of significant .Thus the null hypothesis is accepted and research hypothesis is rejected this variables and interpreted that there is no significant relationship between these variables and maternal haemoglobin level.

\section{Section 5: Association between maternal haemoglobin} level with selected demographic variables

To test the association between the maternal haemoglobin level and selected demographic variables like age, education, religion, family income, residence, age at marriage, duration of married life, weight, BMI, gravida, abortion and living child following null hypothesis was formulated;

$\mathbf{H O}_{2}$ - There will be no significant association between maternal haemoglobin level and selected demographic variables.

The hypothesis was tested using Fisher's exact test

$P$ values of the fisher's tests for the age $(.510, p>0.05)$, education $(.936, p>0.05)$, religion $(p=.721>0.05)$, residence $(.542, p>0.05)$, age at marriage $(.120 p>0.05)$, duration of married life $(.145, p>0.05)$ weight $(.057, p>0.05)$, gravida $(.407 p>0.05)$, abortion(.557p>0.05), living child $(.741 p>0.05)$ is greater than the 0.05 level of significant .Hence the null hypothesis is accepted this variables and which state that there is no significant association between these variables and maternal haemoglobin level.But the values of fisher's test variables like income $(.032, p<0.05)$, body mass index $(.039, p<0.05)$ is less than the 0.05 level of significant .Thus the null hypothesis is rejected and research hypothesis is accepted these variables and interpreted that there is a significant association between these variables and maternal haemoglobin level.

\section{Discussion :}

There is a significant association between maternal haemoglobin level and pregnancy outcome like type of delivery,birth weight.

Study conducted on Risks for preterm delivery and low 
birth weight are independently increased by severity of maternal anaemia. Pearson's chi-square test was used to test the difference between two categorical variables. 95\% confidence intervals ( $\mathrm{Cls}$ ) were calculated. The prevalence of anaemia and severe anaemia was $68 \%$ and $5.8 \%$, respectively. The prevalence of preterm delivery and LBW was $17 \%$ and $14 \%$, respectively. study was conducted to investigate the outcome of pregnancy and delivery in patients with anaemia. 153,396 deliveries, of which 13,204 were anaemic. High rates of preterm deliveries ( $<37$ weeks gestation) and low birth weight $(<2500 \mathrm{gm})$ were found among patients with anemia as compared to the non anemic women (10.7\%versus9.0\%, p<0.001 and 10.5 versus $9.4 \%, p<0.001$ respectively). Higher rates of cesarean section were found among anemia women (20.4\%versus10.3\%; $p<0.001$ )

\section{References :}

1. Bennett VR, Brown LK. Myles textbook for midwives. $13^{\text {th }}$ ed. London: Elsevier Publishers Pvt. Ltd.; 2004.

2. Dutta DC. Text book of obstetrics including perinatology and contraception. New central book agency. Calcutta. 6th edition. 2004.

3. The World Health Report. Reducing risks, promoting healthy life. World Health Organization. Geneva. 2002.248-49.

4. Murphy JF, New combe RG, Coles EG, Pearson JF. Relation of Hemoglobin levels in First and Second Trimesters to Outcome of Pregnancy. Lancet 1986.992-956.

5. Laflamme $\mathrm{M}$ Elise.Maternal $\mathrm{Hb}$ concentration and pregnancy outcome.(serialonline).2007.May;05.Available URL:http://www. mjm. mcgill.ca/orig 13012 .

6. James D.K, Steer P J, Wernier C P, Gonick B. Text book of high risk pregenacy and management option. $3^{\text {rd }}$ ed. Philadelphia. Elsevier Publications. 2006.

7. Sekhaval Leila,D. Robab,somaiasadet 13.H.Relationship between maternal haemoglobin concentration and neonatal birth weight. Haematology Volume 16. November 2011 .pp. 373-376(4)

8. Singh PN, Tyagi M ,Kumar Ashok,Dash D\& Shanker P. Foetal growth in maternal anemia. Internet journal of Nutrition\&wellness.Volume 10.2010.AvailableURL: http://www.ispub.com

\section{Recommendations :}

Based on the findings of the study the following recommendations are put forward for further research.

A study on cause and prevalence of anaemia during pregnancy

- A comparative study can be done on pregnancy outcome in both anaemic and non-anaemic mothers.

- A cohort study on prevalence and contributing factors of anaemia during pregnancy.

\section{Conclusion :}

Anaemia is frequently observed during pregnancy. The study enabled the researcher to identify the association between maternal haemoglobin level and pregnancy outcome. Based on statistical findings, it is evident that there is a significant association between pregnancy outcome. 